\title{
(6) OPEN ACCESS \\ Are Belgian military students in medical sciences better educated in disaster medicine than their civilian colleagues?
}

\author{
Luc J M Mortelmans, ${ }^{1,2}$ J Lievers, ${ }^{3,4} \mathrm{G}$ Dieltiens, ${ }^{1}$ M B Sabbe ${ }^{2,4}$
}

${ }^{1}$ Department of Emergency Medicine, ZNA Camp Stuivenberg, Antwerp, Belgium ${ }^{2}$ Center for Research and Education in Emergency Care, University of Leuven, Leuven, Belgium

${ }^{3}$ Medical Services, Belgian Military, Brussels, Belgium ${ }^{4}$ Department of Emergency Medicine, University Hospita Gasthuisberg, Leuven, Belgium

\section{Correspondence to}

Luc J M Mortelmans,

Department of Emergency

Medicine, ZNA Camp

Stuivenberg, Lange

Beeldekensstraat 267, Antwerp

B2060, Belgium; luc.

mortelmans@zna.be

Received 19 September 2015 Revised 23 November 2015 Accepted 8 December 2015 Published Online First

12 January 2016

\begin{abstract}
Introduction Historically, medical students have been deployed to care for disaster victims but may not have been properly educated to do so. A previous evaluation of senior civilian medical students in Belgium revealed that they are woefully unprepared. Based on the nature of their military training, we hypothesised that military medical students were better educated and prepared than their civilian counterparts for disasters. We evaluated the impact of military training on disaster education in medical science students.
\end{abstract}

Methods Students completed an online survey on disaster medicine, training, and knowledge, tested using a mixed set of 10 theoretical and practical questions. The results were compared with those of a similar evaluation of senior civilian medical students.

Results The response rate was $77.5 \%$, mean age 23 years and $59 \%$ were males. Overall, $95 \%$ of military medical students received some chemical, biological, radiological and nuclear training and 22\% took part in other disaster management training; $44 \%$ perceived it is absolutely necessary that disaster management should be incorporated into the regular curriculum. Self-estimated knowledge ranged from 3.75 on biological incidents to 4.55 on influenza pandemics, based on a 10 -point scale. Intention to respond in case of an incident ranged from 7 in biological incidents to 7.25 in chemical incidents. The mean test score was 5.52; scores improved with educational level attained. A comparison of survey data from civilian senior medical master students revealed that, except for influenza pandemic, military students scored higher on knowledge and capability, even though only $27 \%$ of them were senior master students. Data on willingness to work are comparable between the two groups. Results of the question/case set were significantly better for the military students.

Conclusions The military background and training of these students makes them better prepared for disaster situations than their civilian counterparts.

\section{INTRODUCTION}

In the past, medical students have been involved in direct patient care in large-scale mass casualty incidents; from the Spanish flu pandemic in 1918, flooding, ${ }^{2}$ devastating earthquakes ${ }^{3}{ }^{4}$ to the $9 / 11$ attacks, ${ }^{5}$ medical students have been deployed for the purpose of victim care. The Belgian Royal Academy of Medicine even mentioned them as an important player in the National H5N1 Pandemic Plan in $2005^{6}$ although they were not prepared for it. ${ }^{7}$

A survey on disaster education and knowledge in senior civilian Belgian medical students revealed

\section{Key messages}

Disaster medicine education in medical curricula is scarce and frequently absent.

- The military has a tradition in mass casualty care and chemical, biological, radiological and nuclear incidents.

- Military background makes students in medical sciences better educated in, and prepared for, disaster situations.

some startling concerns: ${ }^{8}$ disaster education is almost absent and knowledge on different disaster situations (except flu pandemics) as well on triage, decontamination and personal protective equipment use is extremely limited. On the other hand, we know that the military has a tradition in humanitarian aid in disaster situations ${ }^{9}$ and possesses extensive knowledge in coping with chemical, biological, radiological and nuclear (CBRN) incidents $;{ }^{10}$ many civilian models of medical disaster response follow the military model. ${ }^{12}$ One could reasonably expect that military training enhances disaster management skills and knowledge. The Belgian Army offers selected personnel the opportunity to follow their university studies in several medical sciences (medicine, dentistry, pharmacology and veterinarian medicine) together with their civilian colleagues in all regular faculties, thus providing for its own medical staff needs.

The aim of this study is to evaluate the impact of basic military training on disaster management education and knowledge, compared with civilian senior medical student colleagues. ${ }^{8}$ The study hypothesis is that military background makes military students better prepared/educated for disaster situations.

\section{MATERIALS AND METHODS}

To evaluate disaster medicine education among Belgian military students in medical sciences, a descriptive cross-sectional study was performed in 2014. The local ethical committee approved the study.

All military students in medical sciences were invited by email to complete an online survey (Survey Monkey, Palo Alto, California, USA) on disaster medicine, training and knowledge (Table 1). The survey queried demographics, prior educational level attained and self-estimated knowledge on, and capability to cope with, several disaster scenarios. Their willingness to work in these 
Table 1 Questions used in the survey. CBRN Chemical, Biological, Radiological, nuclear

\section{What's your native language? Dutch or French}

2. What's your gender? Male or female

3. Age in years?

4. What is your educational study level? Bachelor, Junior Master or Senior Master

5. What is the professional level you hope to reach? Emergency physician, physician, dentist, pharmacist, veterinarian CBRN school 1 year, 1-3 years, 3-7 years, longer than 7 years

8. Do you live within a $20 \mathrm{~km}$ range of a: nuclear installation or high risk chemical installation (Seveso type)?

9. Do you have any association with EMS or disaster management besides your military career?

10. Have you had any lectures or training in disaster medicine/ management?

11. Do you have any knowledge on how to deal with CBRN incidents and/ or affected patients?

12. Do you think that your university training should prepare you one way or another to deal with disaster situations? Absolutely, could be useful, useless

13. On a visual scale from 0 (null) to 10 (expert) what's your estimation of your knowledge on: nuclear incidents, chemical incidents, biological incidents (eg anthrax), epidemic, very contagious disease (eg swine or bird flu), epidemic very contagious disease with high morbidity/mortality risks (eg Ebola)?

14. On a visual scale from 0 to 10 what's your estimation of your capability to deal with patients of: nuclear incidents, chemical incidents, biological incidents (eg anthrax), epidemic, very contagious disease (eg swine or bird flu), epidemic very contagious disease with high morbidity/mortality risks (eg Ebola)?

15. If you were confronted with the following scenarios during your apprenticeship would you engage yourself to actively participate in patient care (on a visual scale from 0 (not at all) to 10 (absolutely))? Nuclear incidents, chemical incidents, biological incidents (eg anthrax), epidemic, very contagious disease (eg swine or bird flu), epidemic very contagious disease with high morbidity/mortality risks (eg Ebola)?

16. Set of theoretical questions: see table 3

circumstances was also assessed. Questions were multiple choice, and self-rated scores were given on a visual analogue scale from 0 to 10 . Knowledge was tested by a mixed set of 10 theoretical questions and practical cases, each correct answer counting as 1 point out of 10 . The survey was developed at the Center for Research and Education in Emergency Care (CREEC) at the University of Leuven and was based on the results of a literature search. It was validated by several disaster specialists. Data were compared with the results of a similar survey (identical except for some demographic data, typical for each group) of senior medical students. ${ }^{8}$

Stata SE V.10.1 (StataCorp LP, College Station, Texas, USA) was used for statistical evaluations. The Pearson $\chi^{2}$ test was used for comparison of proportions/percentages and the two-sample (twosided) $\mathrm{t}$ test was used for comparing means. For comparing medians, the Wilcoxon-Mann-Whitney test was used and normally distributed data were compared using the Pearson correlation coefficient. The Spearman correlation coefficient was used for nonparametric data. A p value $<0.05$ was considered to be significant.

\section{RESULTS}

The response rate of military students in medical sciences was $77.5 \%$, a mean age of 23 years and a male to female ratio of
6. What's the highest level of your CBRN training up to now? None, Basic,

7. What is the timeframe since your last CBRN training period? Less than

59:41. Overall, 54\% of the military students were currently at a bachelor level, 19\% were at a junior master level and 27\% were at the senior master level; $46 \%$ wanted to become an emergency physician, 39\% another type of physician, 12\% pharmacists and $3 \%$ dentists. Some CBRN training ( $2 / 3$ basic level) had been received by $95 \%$ and $22 \%$ had other disaster management training; $71 \%$ felt that they could deal with patients of CBRN incidents. Only $17 \%$ were involved in emergency medical service (EMS) in their spare time but $44 \%$ believed it was absolutely necessary that disaster management should be incorporated in the regular curriculum; only $2 \%$ stated that this training was useless.

Scores on self-estimated knowledge and capability, willingness to work at disasters and mean theoretical-practical test scores of military and civilian students are presented in Table 2. Self-estimated knowledge and capability were well correlated (Spearman $\mathrm{p}<0.005)$. Self-estimated capability for all incident types was significantly higher in the group that knew how to deal with CBRN patients and those students who were involved in EMS. Willingness to assist was strongly correlated with the different scenarios (Spearman $\mathrm{p}<0.0005)$. Students who planned to be pharmacists were significantly less willing to respond to infectious/contagious incidents. Test scores were significantly better in students who had attained higher educational levels. Results on the theoretical-practical questions of the survey are presented in Table 3.

\section{DISCUSSION}

In the event of a mass casualty incident all unaffected, available personnel are expected to help in controlling the situation; every local physician, regardless of specialty, should be able to assist. ${ }^{13}$ When communities become isolated, as in some natural disasters, Family Practice physicians might be the only source of medical expertise available until external help is organised; ${ }^{14}$ for this reason, the Association of American Medical Colleges recommends that all medical schools should thoroughly educate

Table 2 Mean scores on the $0-10$ Visual Analogue Scale on the theoretical-practical case mix test, self-estimated knowledge, self-estimated capability and willingness to work in the listed disaster situations compared with the figures of the senior civilian medical students

\begin{tabular}{lcc}
\hline & Military & Civilian $^{8}$ \\
\hline Mean test score & $5.52 / 10$ & $4.34 / 10^{*}$ \\
Knowledge nuclear incidents & $3.97 / 10$ & $1.81 / 10^{*}$ \\
Knowledge chemical incidents & $4.05 / 10$ & $2.19 / 10^{*}$ \\
Knowledge biological incidents & $3.75 / 10$ & $2.09 / 10^{*}$ \\
Knowledge influenza pandemic & $4.55 / 10$ & $4.61 / 10 \mathrm{~ns}$ \\
Knowledge Ebola outbreak & $4.1 / 10$ & $2.79 / 10^{*}$ \\
Capability nuclear incident & $3.02 / 10$ & $1.61 / 10^{*}$ \\
Capability chemical incident & $3.32 / 10$ & $2.05 / 10^{*}$ \\
Capability biological incident & $3.1 / 10$ & $1.99 / 10^{*}$ \\
Capability influenza pandemic & $4.29 / 10$ & $4.3 / 10 \mathrm{~ns}$ \\
Capability Ebola outbreak & $3.23 / 10$ & $2.55 / 10^{*}$ \\
Willing to work on nuclear incident & $7.1 / 10$ & $7.11 / 10 \mathrm{~ns}$ \\
Willing to work on chemical incident & $7.25 / 10$ & $7.48 / 10 \mathrm{~ns}$ \\
Willing to work on biological incident & $7.0 / 10$ & $7.36 / 10 \mathrm{~ns}$ \\
Willing to work on influenza pandemics & $7.15 / 10$ & $7.7 / 10 \mathrm{~ns}$ \\
Willing to work Ebola outbreak & $7.1 / 10$ & $7.03 / 10 \mathrm{~ns}$ \\
\hline *p<0.05. & & \\
ns, not significant. & &
\end{tabular}


Table 3 Summary of the answers on the theory-case mix questions. The correct answers are in italics. The 'don't know' option was added to eliminate wild guess bias.

\section{Chain collision, possible contaminated patients}

Isolate in distal corner

Put them in waiting room

Put them in garage

Wait separately outside

No action, instead hide

2. lodine tablets protect against

External radiation

Internal radiation

Both external and internal

$10 \%$

No radiation protection at all

Don't know

\section{The regulator means}

Operational leader of overall disaster management $\quad 7.5 \%$

Controlling arriving ambulances

Field hospital supplies

Deciding which patients go where

Don't know

4. Postman with necrotic lesions on his hands, possible

diagnosis

Frostbite

New chemical product in post handling

Possible anthrax infection

Don't know

\section{First step in chemical decontamination}

Oral antidote

Antidote body smear

Antidote spray special military cabin

Wash with water and soap

Don't know

\section{What limits radiation damage the most?}

Protective clothing

Fast decontamination

Oral iodine tablets

Limit time of exposure, increase distance and shielding

Don't know

7. Two most important objects to take along in evacuation (more than 1 possible)

Smartphone

$15 \%$

Laptop

ID/health insurance cards

Syllabus/handbook

Six-pack of beer

Normally used medication

Photo of loved one

None of the above

Don't know

8. Superficial cuts and first degree burns after an explosion at a student party, go to

Nearest hospital

Nearest hospital with burn unit

Home (recover and sleep)

Hospital ED further away

Don't know

\section{Table 3 Continued}

9. First step in nuclear decontamination

Shower patient

$25 \%$

Administer iodine tablets

$10 \%$

Take off clothes and shoes

$47.5 \%$

Put on lead apron

$2.5 \%$

Don't know

10. Traffic accident with 2 trucks (one leaking tanker) and 2 victims, what to do?

Stop, call 112 and help lying victim

Stop, call 112 and help limping victim

Stop at safe distance and wait for clearance fire brigade $\quad 87.5 \%$

Drive by and call 112 at hospital

Act as if nothing happened

their students about disaster medicine in order to bolster a coordinated response to weapons of mass destruction, or to other major acute public health threats. ${ }^{15}$

Recent objective evaluations prove that disaster education of medical students is still limited, provoking a call for instituting a national medical disaster-training curriculum. ${ }^{16}{ }^{17}$ Looking at the status of this kind of education presently in Europe, Germany is the only country with a well-established curriculum, ${ }^{18}$ Italy is in the experimental phase of testing such a programme and using these educational methods in several medical schools ${ }^{19}$ with motivated students expressing the clear need to do so. ${ }^{20}$ Belgium has a limited introduction of such an educational programme in three faculties, ${ }^{8}$ and the Netherlands has no disaster medicine programmes in their medical schools, but one faculty has expressed interest after participating in a recent national survey. ${ }^{21}$

If these military student data are compared with those of a similar survey given to civilian senior master medical students, significantly higher score on self-estimated knowledge and capability is observed, although only $27 \%$ were senior master students; one exception regards the knowledge and capability of influenza pandemics. Results on willingness to work in various disaster scenarios are comparable between the two groups, and the results of the theoretical question/case section were significantly more favourable for the military student group.

The data support our study hypothesis that a military background makes students in medical sciences better prepared and educated for disaster situations. They score better in selfestimated knowledge and capability, as well as in the theoretical questions/practical case mix part of the survey. Taking into account that only about one quarter of the study population were senior master students and that seniority was an important promoting factor, we are compelled to notice the positive impact of basic military training on disaster management. The only exception was for the influenza pandemic scenario, in which both civilian and military students performed comparably, which is probably because this subject is now extensively covered in the regular medical science curriculum, after it was seen to be lacking before the most recent influenza pandemic threats. It should also be stressed that this survey was administered before the recent West African Ebola outbreak emerged so publicly, so the virtual Ebola outbreak scenario in the survey was recognised only as a dangerous unknown.

The scores on the set of 10 practical and theoretical questions were compared with those obtained in the study with civilian 
senior master medical students, revealing that performance on this part was also significant higher in the military group. Taking into account that $55 \%$ of the military students would use antidotes instead of water and soap as a first step in chemical decontamination, as this is taught in their CBRN courses, the difference could even be greater. Only $20 \%$ of the military students reported that they would put potentially contaminated victims of a chain collision in the waiting room, whereas half of their civilian counterparts said they would; the use of iodine tablets in nuclear scenarios is also better known: only 25\% believed that they protected against external radiation compared with $47 \%$ of civilians and only $10 \%$ of military students would use iodine tablets as a first step in nuclear decontamination versus $48 \%$ of civilian students. Knowledge that limiting time of exposure, increasing distance and shielding limits radiation damage the most was higher in the military students $(90 \%$ vs $78 \%$ ) and more would not go uninformed and unprotected into a traffic accident involving leaking tanker versus $(87.5 \%$ vs $65 \%)$.

Giving this outcome, it can be stated that basic military training and background makes the military medical sciences student better educated and prepared for disaster situations than their civilian counterparts. This result suggests the need for greater involvement of the military in disaster medicine training and education, as is common in other countries. ${ }^{22}$ The ideal situation would be one that evolves into a basic disaster medicine education in the regular national medical education curriculum with a clear input from military knowledge and experience. However, up to now this possibility is not even in a nascent stage. Our centre is delighted to have an established joint venture with the military in its disaster management course but unfortunately this is only at a postgraduate level.

This study has some limitations in that the use of surveys and self-reported data could result in collecting bias; on the other hand, we compared these data with those of a similar study using the same methods and bias, so we may conclude that the comparison is at least consistent.

\section{CONCLUSION}

Basic military training and its associated background make the military population better educated and prepared for disaster situations than their civilian counterparts.

Acknowledgements The authors thank General-Major Laire, MD, Head of the Medical Component of the Belgian Military for his support in this study project and the Belgian Society of Emergency and Disaster Medicine (Besedim) for the use of their Survey Monkey account.

Contributors LJMM wrote the manuscript, was involved in the survey design and performed the literature search. $\mathrm{JL}$ adapted the survey to the military situation and recruited the respondents. GD performed the statistical analysis. MBS launched the study concept, was involved in the survey design and was the liaison with the military command. LJMM is responsible as guarantor.

Competing interests None declared.

Ethics approval ZNA Antwerp Ethical Committee.
Provenance and peer review Not commissioned; externally peer reviewed.

Open Access This is an Open Access article distributed in accordance with the Creative Commons Attribution Non Commercial (CC BY-NC 4.0) license, which permits others to distribute, remix, adapt, build upon this work non-commercially, and license their derivative works on different terms, provided the original work is properly cited and the use is non-commercial. See: http://creativecommons.org/ licenses/by-nc/4.0/

\section{REFERENCES}

1 Starr I. Influenza in 1918: recollections of the epidemic in Philadelphia. Ann Intern Med 2006:145:138-40.

2 Kshirsagar NA, Shinde RR, Mehta S. Floods in Mumbai: impact of public health service by hospital staff and medical students. J Postgrad Med 2006;52:312-14.

3 Reyes H. Student's response to disaster: a lesson for health care professional schools. Ann Intern Med 2010;153:658-60.

4 Sabri AA, Qayyum MA. Why medical students should be trained in disaster management: our experience of the Kashmir Earthquake. PLoS Med 2006;3:1452-3.

5 Katz CL, Gluck N, Maurizio A, et al. The medical student experience with disasters and disaster response. CNS Spectr 2002;7:604-10.

6 Belgian Royal Academy of Medicine. The coming influenza epidemic: a reason to prepare. Belg Tijdschr Gen 2005;61:1577-82.

7 Mortelmans LJM, De Cauwer HG, Van Dyck E, et al. Are Belgian senior medical students ready to deliver basic medical care in case of a H5N1 pandemic? Prehosp Disaster Med 2009;24:438-42.

8 Mortelmans LJM, Dieltiens G, Anseeuw K, et al. Belgian senior medical students and disaster medicine, a real disaster? Eur J Emerg Med 2014;21:77-8.

9 DeZee KJ, Berbano EP, Wilson RL, et al. Humanitarian assistance medicine: perceptions of preparedness: a survey based needs assessment of recent U.S. Army internal medicine residency graduates. Mil Med 2006;171:885-8.

10 Cieslak TJ, Pavlin JA, Noah DL, et al. Military medical education: nuclear, biological and chemical defense training as a model for planners. Mil Med 2004;169:337-41.

11 Sharma M. Chemical, biological, radiological and nuclear training issues in India: a fresh perspective. J Pharm Bioallied Sci 2010;2:275-80.

12 Dara SI, Ashton RW, Farmer JC, et al. Worldwide disaster medical response: an historical perspective. Crit Care Med 2005;33(Suppl 1):S2-6.

13 Kaji AH, Coates W, Fung CC. A disaster medicine curriculum for medical students. Teach Learn Med 2010;22:116-22.

14 Huntington MK, Gavagan TF. Disaster medicine training in family medicine: a review of the evidence. Fam Med 2011;43:13-20.

15 Parrish AR, Oliver $S$, Jenkins $D$, et al. A short medical school course on responding to bioterrorism and other disasters. Acad Med 2005;80:820-3.

16 Kaiser HE, Barnett DJ, Hsu EB, et al. Perspectives of future physicians on disaster medicine and public health preparedness: challenges of building a capable and sustainable auxiliary medical workforce. Disaster Med Public Health Prep 2009;3:210-16.

17 Jasper E, Berg K, Reid M, et al. Disaster preparedness: what training do our interns receive during medical school? Am J Med Qual 2013;28:407-13.

18 Pfenninger EG, Domres BD, Stahl W, et al. Medical student disaster medicine education: the development of an educational resource. Int J Emerg Med 2010;3:9-20.

19 Ingrassia PL, Ragazzoni L, Tengattini M, et al. Nationwide program of education for undergraduates in the field of disaster medicine: development of a core curriculum centered on blended learning and simulation tools. Prehosp Disaster Med 2014;29:508-15.

20 Ragazzoni L, Ingrassia PL, Gugliotta G, et al. Italian medical students and disaster medicine: awareness and formative needs. Am J Disaster Med 2013:8:127-36.

21 Mortelmans LJM, Bouman S, Gaakeer MI, et al. Dutch senior medical students and disaster medicine: a national survey. Int J Emerg Med 2015;8:34.

22 Bayala ZA, Rüttiman M. Training in disaster medicine in Africa: where are we in 2013? Med Sante Trop 2013;23:233. 